\title{
ANALISIS PROSES PRODUKSI DUDUKAN KOMPRESOR MESIN PENDINGIN
}

\author{
Heru Saptono, Siti Suwaibah, Bambang Tjahyono \\ Jurusan Teknik Mesin, Politeknik Negeri Semarang \\ Program Studi D3 Teknik Mesin Jurusan Teknik Mesin Politeknik Negeri Semarang \\ Jl. Prof. H. Sudarto, S.H., Tembalang, Kotak Pos 6199/SMS, Semarang 50329 \\ Telp. 7473417, 7466420 (Hunting), Fax. 7472396
}

\begin{abstract}
Abstrak
Press tool merupakan suatu alat yang mempunyai prinsip kerja penekanan dengan melakukan pemotongan, pembentukan atau gabungan dari keduanya. Peralatan yang digunakan untuk membuat produk secara masal dengan output yang sama dalam waktu yang relatif singkat. Jenis press tool yang digunakan dalam analisa dudukan kompresor mesin pendingin ini adalah jenis compound tool. Dudukan kompresor mesin pendingin merupakan salah satu komponen pada mesin pendingin. Dudukan kompresor mesin pendingin dibentuk dengan press tool, ada 6 proses produksi yang mencakup proses blanking, pierching, deep drawing, bending, embossing. Gaya total yang terbesar terletak pada proses produksi 1 yaitu sebesar 509477,421 N yang membutuhkan mesin press kapasitas 60 ton. Dudukan kompresor mesin pendingin ini terbuat dari gulungan pelat dengan pengerjaan dingin (SPCC) dengan ketebalan $1 \mathrm{~mm}$. Dalam produksi dudukan kompresor mesin pendingin ini diperkirakan terjadi kecacatan sebesar 3\% dari total produksi perhari meliputi benda berkerut maupun sobek.
\end{abstract}

Kata Kunci : “press tool”, “dudukan kompresor mesin pendingin”, “kecacatan”

\section{Pendahuluan}

Dudukan kompresor juga sebagai penstabil kompresor, karena apabila kompresor langsung berada dilantai maka akan terjadi perubahan suhu yang terjadi pada lantai yang menyebabkan kerja kompresor terhambat. Apabila suhu ruangan semakin panas, dan kompresor berada di lantai maka kerja kompresor akan besar sehingga listrik yang dikonsumsi lebih besar. Selain kerja kompresor terhambat, panas yang dihasilkan kompresor akan tersalurkan ke lantai secara langsung, apabila lantai tersebut dilapisi oleh karpet maka lama kelamaan karpet tersebut akan terbakar karena panas yang dihasilkan oleh kompresor. Oleh sebab itu dudukan kompresor sangat diperlukan pada mesin pendingin karena perannya yang sangan berarti saat pemakaian mesin pendingin. Dudukan kompresor mesin pendingin tersebut dapat dibuat menggunakan mesin press dengan bantuan alat cetak.

\section{Metodologi Penelitian Dan Perhitungan}

Bahan yang digunakan dalam penelitian ini adalah lembaran pelat dengan dimensi ukuran panjang $562 \mathrm{~mm}$, lebar $235 \mathrm{~mm}$, serta tebal $1 \mathrm{~mm}$. Lembaran pelat yang dipakai adalah jenis gulungan pelat dengan pengerjaan dingin (SPCC/Steel Plate Cold Coiled) dengan standart Jepang. SPCC memiliki tegangan tarik bahan sebesar 270 $\mathrm{N} / \mathrm{mm}^{2}$. Alat yang dipergunakan dalam penelitian ini adalah mesin press dan alat cetak. Mesin press yang digunakan adalah mesin press dengan kapasitas 60 ton. Dengan daya mesin sebesar $5,5 \mathrm{~kW}$.

Dalam melaksanakan penyusunan tugas akhir ini beberapa metode digunakan penulis dalam mengumpulkan data-data antara lain sebagai berikut:

Survei lapangan

Survei lapangan digunakan untuk mendapatkan data-data yang diperlukan dalam penelitian yang diambil dari magang industri di PT Nagamas Cahaya Sentosa. 
Wawancara

Wawancara dilakukan dengan operator mesin press bagian assembling dan bagian quality control di PT Nagamas Cahaya Sentosa mengenai data kecacatan, cara produksi dudukan kompresor mesin pendingin.

Studi pustaka

Studi pustaka didapatkan dari buku-buku, jurnal yang berkaitan dengan press tool, proses pengerjaan press tool, break event point, pengendalian mutu untuk dasar dari perhitungan dan penyusunan penelitian.

Perhitungan gaya yang terjadi pada mesin press pada setiap proses dapat dilihat pada tabel 1 . berikut ini.

Tabel 1. Gava nada Mesin Press

\begin{tabular}{|c|c|c|c|c|}
\hline No. & Proses Pengerjaan & Gaya $[\mathrm{N}]$ & Jumlah Pengerjaan & Jumlah Gaya [N] \\
\hline \multicolumn{5}{|c|}{ PROSES PENGEPRESAN I } \\
\hline 1. & Blanking & 315884,88 & 1 & 315884,88 \\
\hline 2. & Bending 1 & 1413,36 & 1 & 1413,36 \\
\hline 3. & Bending 2 & 1979,28 & 1 & 1979,28 \\
\hline 4. & Deep Drawing 1 & 23929,586 & 4 & 95718,344 \\
\hline 5. & Deep Drawing 2 & 94481,557 & 1 & 94481,557 \\
\hline \multicolumn{4}{|c|}{ GAYA TOTAL } & 509477,421 \\
\hline \multirow{2}{*}{\multicolumn{4}{|c|}{$\begin{array}{l}\text { GAYA STRIPPER }(10 \% \text { x GAYA TOTAL }) \\
\text { GAYA TOTAL MESIN I }\end{array}$}} & 50947,7421 \\
\hline & & & & 560425,1631 \\
\hline \multicolumn{5}{|c|}{ PROSES PENGEPRESAN II } \\
\hline 6. & Pierching 1 & 322503,12 & 1 & 322503,12 \\
\hline 7. & Pierching 2 & 5428,728 & 2 & 10857,456 \\
\hline \multicolumn{4}{|c|}{ TOTAL } & 333360,576 \\
\hline \multicolumn{4}{|c|}{ GAYA STRIPPER $(10 \% \times$ GAYA TOTAL $)$} & 33336,0576 \\
\hline \multicolumn{4}{|c|}{ GAYA TOTAL MESIN II } & 366696,6336 \\
\hline
\end{tabular}

\begin{tabular}{|c|c|c|c|c|}
\hline \multicolumn{5}{|c|}{ PROSES PENGEPRESAN III } \\
\hline 8. & Embossing 1 & 6413,843 & 2 & 12827,686 \\
\hline 9. & Embossing 2 & 13703,843 & 1 & 13703,843 \\
\hline 10. & Embossing 3 & 12083,843 & 2 & 24167,686 \\
\hline 11. & Embossing 4 & 38813,843 & 1 & 38813,843 \\
\hline 12. & Deep Drawing 1 & 8468,6 & 1 & 8468,6 \\
\hline 13. & Deep Drawing 2 & 11164,5 & 2 & 22329 \\
\hline 14. & Deep Drawing 3 & 11046,739 & 2 & 22093,478 \\
\hline 15. & Deep Drawing 4 & 14867,71 & 2 & 29735,42 \\
\hline 16. & Deep Drawing 5 & 5428,672 & 1 & 5428,672 \\
\hline 17. & Deep Drawing 6 & 13633,399 & 2 & 27266,798 \\
\hline \multicolumn{4}{|c|}{ TOTAL } & 204835,026 \\
\hline \multicolumn{4}{|c|}{ GAYA STRIPPER ( $10 \%$ x GAYA TOTAL) } & 20483,5026 \\
\hline \multicolumn{4}{|c|}{ GAYA TOTAL MESIN III } & 225318,5286 \\
\hline \multicolumn{5}{|c|}{ PROSES PENGEPRESAN IV } \\
\hline 18. & Pierching & 30110,4 & 4 & 120441,6 \\
\hline 19. & Bending & 32904 & 1 & 32904 \\
\hline \multicolumn{4}{|c|}{ TOTAL } & 153345,6 \\
\hline \multirow{2}{*}{\multicolumn{4}{|c|}{$\begin{array}{c}\text { GAYA STRIPPER ( }(10 \% \text { x GAYA TOTAL }) \\
\text { GAYA TOTAL MESIN IV }\end{array}$}} & 15334,56 \\
\hline & & & & 168680,16 \\
\hline
\end{tabular}

\begin{tabular}{|c|c|c|c|c|}
\hline \multicolumn{5}{|c|}{ PROSES PENGEPRESAN V } \\
\hline 20. & Pierching 1 & 1764,288 & 1 & 1764,288 \\
\hline 21. & Pierching 2 & 6046,056 & 2 & 12092,112 \\
\hline 22. & Pierching 3 & 4071,384 & 1 & 4071,384 \\
\hline 23. & Pierching 4 & 4750,056 & 2 & 9500,112 \\
\hline 24. & Pierching 5 & 2035,8 & 1 & 2035,8 \\
\hline 25. & Bending & 32904 & 1 & 32904 \\
\hline \multicolumn{4}{|c|}{ TOTAL } & 62367,696 \\
\hline \multirow{2}{*}{\multicolumn{4}{|c|}{$\begin{array}{c}\text { GAYA STRIPPER }(10 \% \times \text { GAYA TOTAL) } \\
\text { GAYA TOTAL MESIN V }\end{array}$}} & 6236,7696 \\
\hline & & & & 68604,4656 \\
\hline \multicolumn{5}{|c|}{ PROSES PENGEPRESAN VI } \\
\hline 26. & Bending 1 & 918 & 4 & 3672 \\
\hline 27. & Bending 2 & 32904 & 1 & 32904 \\
\hline \multicolumn{4}{|c|}{ TOTAL } & 36576 \\
\hline \multicolumn{4}{|c|}{ GAYA STRIPPER ( $10 \%$ x GAYA TOTAL) } & 3657,6 \\
\hline & GA & OTAL ME & VI & 40233,6 \\
\hline
\end{tabular}

Berikut adalah gambaran proses produksi dari dudukan kompresor mesin pendingin yang terdapat pada gambar 1 .

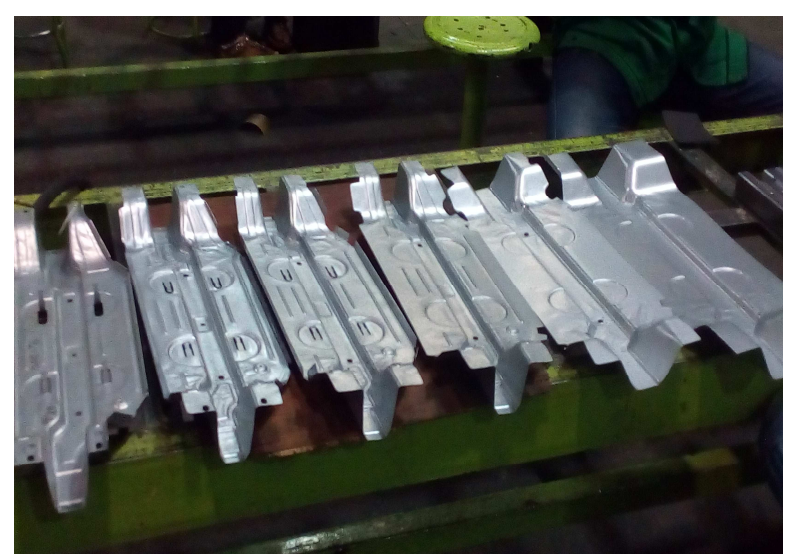

Gambar 1. Hasil Produksi

Dari gambar 1. hasil produksi kanan ke kiri merupakan proses produksi dari proses pengerjaan pertama sampai proses pengerjaan keenam menggunakan mesin press.

\section{Pembahasan}

Dudukan kompresor mesin pendingin terbuat dari gulungan pelat pengerjaan dingin (Steel Plate Cold Coiled/SPCC) dengan tebal 1 $\mathrm{mm}$. Pada awal produksi dibutuhkan lembaran pelat dengan ukuran panjang 562 $\mathrm{mm}$ dan lebar $235 \mathrm{~mm}$ untuk rencana produk dudukan kompresor mesin pendingin. Proses produksi dimulai dari proses pertama yaitu proses pembentukan meliputi proses drawing dan proses bending serta proses pemotongan berupa pemotongan bagian tepi pelat (blanking). Proses kedua dari lembaran pelat hanya berupa proses pemotongan yang meliputi proses pemotongan tepi pelat membentuk sebuah pola (trimming) dan proses pierching. Proses ketiga dan keempat menggunakan satu alat cetak yang mempunyai nama proses ristake bending. Proses ristake merupakan nama dari proses ketiga. Proses ristrake sendiri merupakan lanjutan dari proses drawing, dimana material akan mengalami penekanan sehingga membentuk suatu kedalaman tertentu dengan bentuk yang diharapkan. 
Proses keempat ini hanya mengerjakan dua proses yaitu proses pembentukan berupa proses bending $90^{\circ}$ pada bagian tepi yang merupakan hasil dari proses trimming pada proses kedua. Proses kelima menggunakan alat cetak dengan nama proses pierching karena proses kelima hanya ada dua proses yaitu proses pembentukan berupa bending dan proses pemotongan berupa pierching sedangkan proses pierching lebih dominan pada proses ini. Proses terakhir pengepresan menggunakan alat cetak dengan nama proses hemming. Hamming adalah suatu proses penekukan atau pelipatan (bending) pada bagian tepi material untuk memperkuat, menghilangkan bagian yang tajam serta memperbaiki estetika produk tersebut.

Dari produksi dudukan kompresor mesin pendingin terdapat enam proses dimana setiap proses tersebut saling berkaitan untuk memperoleh suatu produk jadi. Setiap hari perusahaan diharapkan menghasilkan 800 unit produk jadi dengan harapan kecacatan yang dicapai maksimal sebesar $3 \%$ pada setiap hari produksi. Perhitungan kecacatan tersebut bukan pada setiap prosesnya namun dihitung akumulasi keseluruhan prosesnya. Jadi, untuk menghasilkan 800 unit produk jadi maksimal produk gagal sebanyak 24 unit produk. Penelitian tugas akhir ini menggunakan analisis dalam waktu lima hari kerja. Dimana setiap hari kerja menghasilkan 800 produk yang di dapatkan dari sebuah perusahaan press tool di Semarang.

Tabel 2. Data kecacatan produk dalam lima hari kerja

\begin{tabular}{|c|c|c|c|c|c|c|c|c|c|}
\hline \multirow{2}{*}{ No. } & $\begin{array}{c}\text { Jenis } \\
\text { Kecacatan }\end{array}$ & $\begin{array}{l}\text { Hari } \\
1\end{array}$ & $\begin{array}{l}\text { Hari } \\
2\end{array}$ & $\begin{array}{l}\text { Hari } \\
3\end{array}$ & $\begin{array}{l}\text { Hari } \\
4\end{array}$ & $\begin{array}{l}\text { Hari } \\
5\end{array}$ & $\begin{array}{l}\text { Rata- } \\
\text { rata }\end{array}$ & $\%$ & $\begin{array}{c}\% \\
\text { kumulatif }\end{array}$ \\
\hline 1 & $\begin{array}{l}\text { Permukaan } \\
\text { keriput } \\
\text { (wringkles) }\end{array}$ & 13 & 9 & 7 & 5 & 8 & 8,4 & 50 & $50 \%$ \\
\hline 2 & Produk sobek & 9 & 4 & 3 & 4 & 2 & 4,4 & 26,2 & $76,2 \%$ \\
\hline 3 & $\begin{array}{l}\text { Pelengkungan } \\
\text { tepian hasil } \\
\text { piercing }\end{array}$ & 2 & 5 & 3 & 5 & 5 & 4 & 23,8 & $100 \%$ \\
\hline & Jumlah & 24 & 18 & 13 & 14 & 15 & 16,8 & 100 & \\
\hline
\end{tabular}

Dari tabel 2. diatas dapat diketahui bahwa produk cacat yang dihasilkan dalam satu hari produksi adalah 24 produk. Hasil ini melebihi kecacatan yang diperkirakan. Namun, tidak semua produk cacat tersebut langsung menjadi scrap. Ada beberapa yang dapat diperbaiki misalkan produk cacat akibat pierching yang gagal. Kata gagal disini berarti pierching belum seutuhnya terpotong, maka produk tersebut dapat diperbaiki lagi dengan cara pengepressan ulang. Tabel kecacatan tersebut dapat dibuat dalam bentuk diagram pareto seperti berikut.

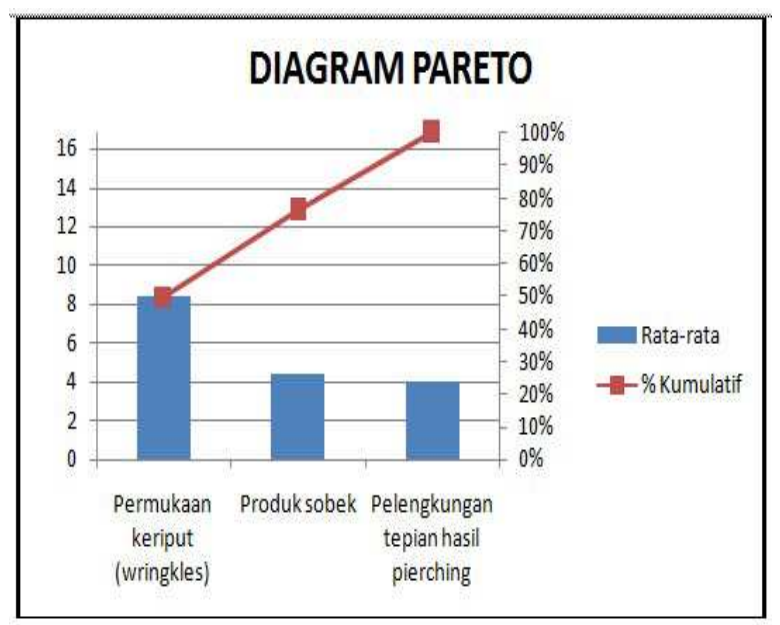

Gambar 2. Diagram Pareto

Dari analisa menggunakan diagram pareto didapatkan bahwa permukaan benda kerja yang keriput (wringkles) akan menjadi perhatian dalam menganalisa penyebab kecacatan tersebut. Penyebab kecacatan dapat berasal dari faktor manusia, mesin, bahan, metode, lingkungan dan lain sebagainya.

Kecacatan produk yang menghasilkan produk keriput disebabkan oleh operator yang ceroboh dalam mensetting mesin yang mengakibatkan punch dan die tidak pas (tidak center) yang mengakibatkan clearance punch juga tidak center. Selain itu, kurang seringnya melakukan pelumasan pada punch dan die yang menyebabkan pengepresan kurang licin. 
Selain faktor tersebut benda keriput juga dapat disebabkan oleh pelat yang terjepit punch sehingga terjadi pelekukan di dalam punch. Kecacatan juga dapat disebabkan oleh spring yang kurang kencang sehingga stripper plate kurang kuat untuk menahan benda kerja. Bahan yang digunakan harus sesuai dengan perancangan awal yaitu menggunakan pelat SPCC dengan ketebalan $1 \mathrm{~mm}$. Apabila bahan yang digunakan memiliki tegangan tarik yang lebih besar (lebih keras) maupun lebih tebal maka produk yang dihasilkan akan mengalami keriput dan kecacatan lain. Dari produksi dudukan kompresor mesin pendingin dan penjualan produk tersebut dapat dihitung Break Event Point (BEP) atau titik impas yang ditunjukkan dengan diagram BEP berikut ini.

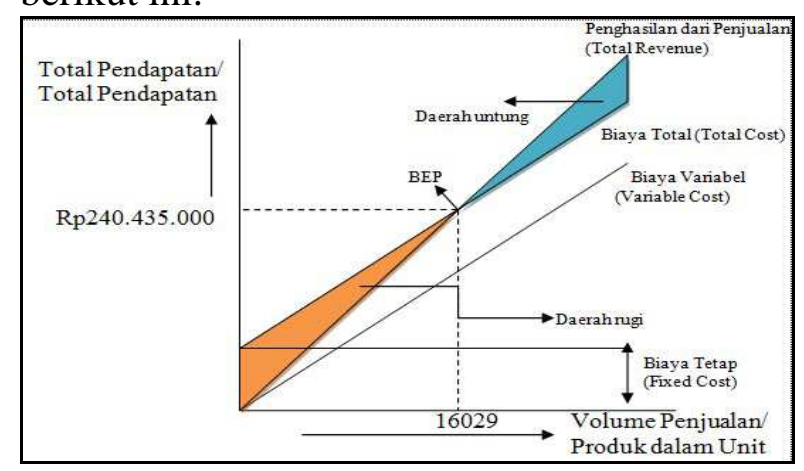

\section{Gambar 3. Diagram BEP}

Dari diagram BEP tersebut dapat dilihat bahwa titik impas atau Break Event Point terdapat pada volume penjualan sebesar 16.029 unit produk. Sedangkan dalam bentuk rupiah dapat dihitung dengan mengalikan volume tersebut dengan harga jual sehingga diperoleh hasil $\mathrm{Rp} 240.435 .000$.

\section{Kesimpulan dan Saran}

Proses pembuatan dudukan kompresor mesin pendingin melalui enam kali pengepresan dengan menggunakan enam alat cetak. Dari proses produksi terdapat kecacatan maksimal sebesar 3\% dari produk jadi, sehingga diharapkan hanya ada maksimal 24 produk cacat. Kecacatan yang dianalisis penyebabnya hanya permukaan yang keriput karena mempunyai presentase kecacatan yang paling besar.

Dari diagram BEP dapat dilihat bahwa titik impas atau Break Event Point terdapat pada volume penjualan sebesar 16.029 unit produk.

\section{Saran}

Dari penulisan tugas akhir ini, disarankan agar peneliti selanjutnya dapat:

a. Menganalisa penyebab kecacatan produk serta solusi yang lebih banyak.

b. Variasi ketebalan pelat perlu dilakukan untuk mendapatkan data-data yang kemungkinan dapat digunakan.

\section{Daftar Pustaka}

- Anonim. Tanpa Tahun. Dunia Merek 25 Ton 45 Ton 60 Ton Daya Mesin Press untuk Dijual. https://indonesian.alibaba.com. Diaksespada 1 Agustus 2018.

- Charli. Tanpa Tahun. Analisis Hasil Pemotongan Press Tool Pemotongan Strip Plat pada Mesin Tekuk Hidrolik Promecam di Laboratorium Pemesinan. Semarang: Politeknik Negeri Semarang.

- Jutz, Hermann dan Eduard Scharkus. 1985. Westermann Tables for The Metal Trade. New Delhi: Wiley Eastern Limited.

- Khosa, Parmindersingh, Chirag Hiremath, et al. 2015. "Design and Manufacturing of Progressive Press Tool'. International Journal of Advances in Mechanical and Civil Engineering. Volume 2, Nomer 1, Hal 20-22.

- Nee, John G.. 2010. Fundamentals of Tool

Design Sixth Edition. Michigan: Society of Manufacturing Engineering. 
- Ostergaard, D. Eugene. 1963. Basic Die Making. New York: Mcgraw-Hill Book Company, Inc.

- Patriatna, Endjang dan Hanif Azis Budiarto. Tanpa Tahun. Perancangan Combination Tool Proses Cutting dan Forming pada Pembuatan Alumunium Cup. Bandung: Politeknik Manufaktur Negeri Bandung.
- Rizza, Muhammad Akhlis. 2014. "Analisis Proses Blanking dengan Simple Press Tool'. Jurnal Rekayasa Mesin. Volume 5, Nomer 1, Hal 8590. Malang.

- Wick, Charles. 1984. Tool and Manufacturing Handbook Fourth Edition. Michigan: Society of Manufacturing Engineers. 